\title{
Tanınız nedir?
}

\section{What is your diagnosis?}

\section{Berna Aksoy, Hasan Mete Aksoy*, Onat Akın**}

Bahçeșehir Üniversitesi Tıp Fakültesi, Dermatoloji Anabilim Dalı, İstanbul; VM Medicalpark Hastanesi, Dermatoloji Kliniği, Kocaeli, Türkiye

*Serbest Hekim, Plastik ve Rekonstrüktif Cerrahi Uzmanı, Kocaeli, Türkiye

**Patomed Patoloji Laboratuvarı, İstanbul, Türkiye

Kırk iki yaşında erkek hasta dermatoloji polikliniğine gövdede 15 günden beri var olan ve hızı büyüyen kitle nedeniyle başvurdu. Lezyonda kaşıntı ya da kanama yoktu. Travma öyküsü bulunmuyordu. Özgeçmiş ve soygeçmişinde özellik yoktu. Dermatolojik muayenede gövde sol tarafında yerleşmiş, 15×10 mm boyutlarında, hedef şeklinde, kırmızı mor plak ve çevreleyen mor halka tespit edildi (Resim 1). Dermatolojik incelemede lezyonun halka kısmında ekimozla uyumlu kırmızı mor homojen yapısız alanlar görüldü. Lezyonun orta kısmında kırmızı mor gölcük benzeri yapılar, kırmızımsı kurutlar ve homojen kırmızı yapısız alanlar mevcuttu. Gölcük benzeri alanları çevreleyen lineer beyaz çit benzeri yapılar da gözlendi (Resim 2). Kitlenin tamamı eksize edildi. Histopatolojik kesitlerde subepidermal ve yüzeyel dermal lokasyonda yerleşmiş düzensiz vasküler boşluklardan oluşan hafif polipoid lezyon görüldü. Vasküler lümenler eritrositler ile dolu ve belirgin endotelyal hücreler ile çevriliydi. Bazı endotelyal hücreler kabara çivisi görünümündeydi. Sellüler atipi veya nükleer pleomorfizm saptanmadı. Aradaki stroma hafif sellüler, fibröz görünümde ve dağınık lenfositler içermekteydi (Resim 3, 4). Mevcut klinik ve histopatolojik bulgular eşliğinde tanınız nedir?

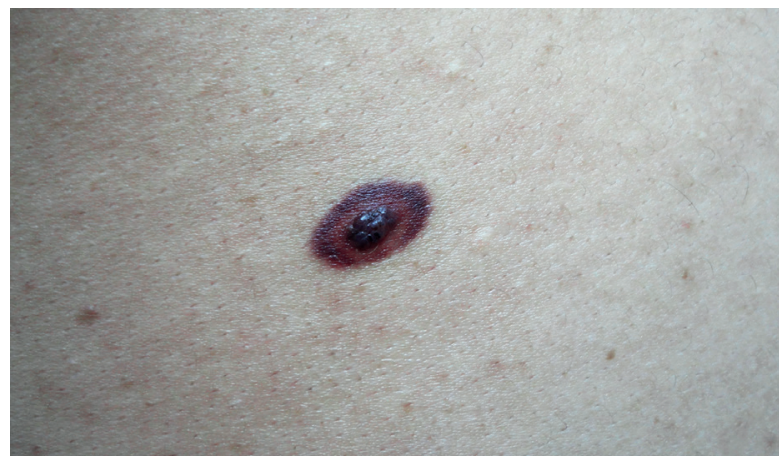

Resim 1. Gövdede yerleşmiş hedef benzeri lezyon

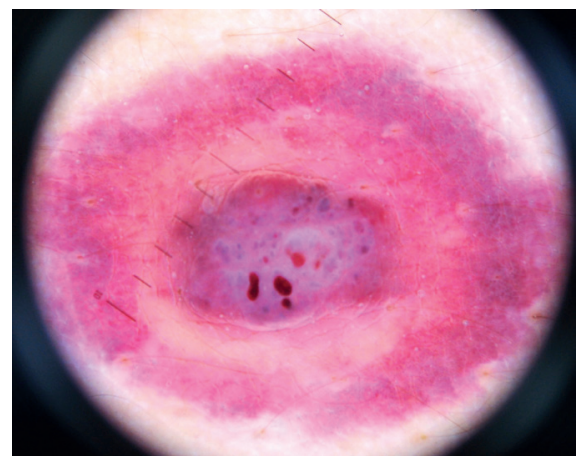

Resim 2. Lezyonun dermoskopik görünümü

\footnotetext{
Yazışma Adresi/Address for Correspondence: Dr. Berna Aksoy, Bahçeşehir Üniversitesi Tıp Fakültesi, Dermatoloji Anabilim Dalı, İstanbul; VM Medicalpark Hastanesi, Dermatoloji Kliniği, Kocaeli, Türkiye Tel.: +90 5326665634 E-posta: bmaksoy@mynet.com Geliş Tarihi/Received: 13.03.2016 Kabul Tarihi/Accepted: 16.06.2016

(c) Telif Hakkı 2017 Deri ve Zührevi Hastalılar Derneği

Türkderm-Deri Hastalıkları ve Frengi Arșivi Dergisi, Galenos Yayınevi tarafından basılmıștır.
} 


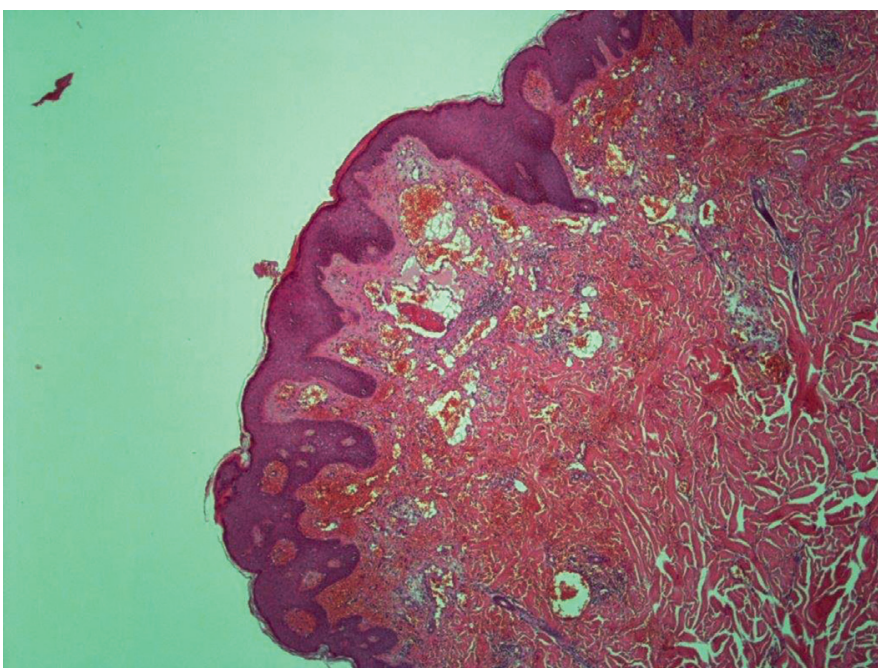

Resim 3. Polipoid vasküler lezyon (hematoksilen\&eozin x40)

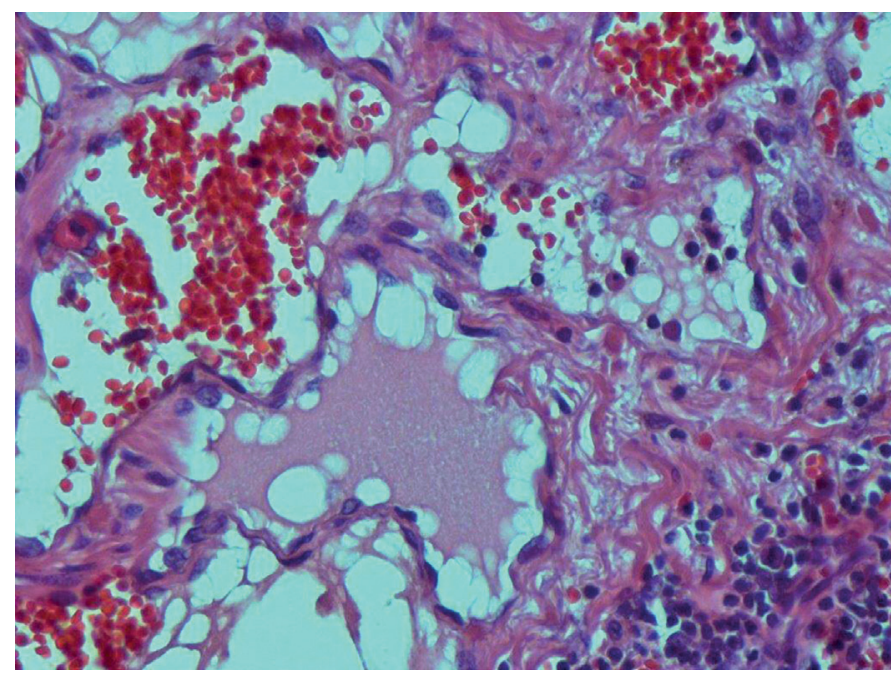

Resim 4. Bazıları kabara çivisi görünümlü endotelyal hücreler içeren irregüler dilate damarlar (hematoksilen\&eozin x400)

\section{Tanı: Kabara çivisi hemanjiyomu}

Kabara çivisi hemanjïomu ilk olarak 1988 yılında targetoid hemosiderotik hemanjiyom olarak tanımlanmıştır'. Klinik olarak violase papülü çevreleyen ekimotik veya kahverengi halkadan oluşan hedef benzeri görünümle karakterizedir'. Kabara çivisi hemanjiyomu histopatolojik incelemede tipik olarak kabara çivisi görünümündeki endotelyal hücreler ile döşeli vasküler kanallar içerir'. Kabara çivisi hemanjïomlar sıklıkla gövde ve ekstremite derisinde yerleşim gösterirler'. Edinsel vasküler malformasyonlardır ve travma sonrası ortaya çıkabilirler². Östrojen ve progesteronun vazoaktif ajanlar olarak etki göstermesi bu lezyonların gelişiminde rol oynayabilir². Sunulan olgu tanımlanan ilk olguya benzer tipik bir kliniğe sahipti ve morumsu papülü çevreleyen soluk kenar ve çevreleyen morumsu ekimotik halka içermekteydi. Dermatoskopik inceleme ayırıcı tanıda yardımcı olabilir. Bu lezyonların dermatoskopik bulguları gölcük benzeri alanlar, arada beyaz çizgisel ve kırmızımsı yapısız alanlar ve bunları nadiren çevreleyen kırmızımsı halka ve kurutlardı4, ${ }^{4}$. Kabara çivisi hemanjiyomlar zaman içinde tekrarlanan siklik morfolojik değişiklikler gösterebilir ve bu durum özellikle kadınlarda hormonal etkiler nedeniyle görülürt. Kabara çivisi hemanjïyomunun başlangıçta iyi huylu vasküler bir tümör olduğuna inanılmaktaydı ancak son zamanlarda yapılan immünohistokimyasal çalısmalar sonucunda lenfatik malformasyon olarak sınıflandırılması gerektiği ortaya çıkmışır'. Kabara çivisi hemanjiyom basit eksizyon ile tedavi edilebilen, bildirilmiş nüks ya da metastazı olmayan iyi huylu bir oluşumdur².

\section{Etik}

Hasta Onayı: Çalışmamıza dahil edilen tüm hastalardan bilgilendirilmiş onam formu alınmıştır.

Hakem Değerlendirmesi: Editörler kurulu tarafından değerlendirilmiştir.

\section{Yazarlık Katkıları}

Cerrahi ve Medikal Uygulama: H.M.A., B.A., Konsept: B.A., Dizayn: B.A., Veri Toplama veya İsleme: O.A., Analiz veya Yorumlama: O.A., B.A., Literatür Arama: B.A., Yazan: B.A., H.M.A.

Çıkar Çatışması: Yazarlar bu makale ile ilgili olarak herhangi bir çıkar çatışması bildirmemiştir.

Finansal Destek: Çalışmamı için hiçbir kurum ya da kişiden finansal destek alınmamıştır.

\section{References}

1. Trindade F, Kutzner $\mathrm{H}$, Tellechea O, Requena L, Colmenero I: Hobnail hemangioma reclassified as superficial lymphatic malformation: a study of 52 cases. J Am Acad Dermatol 2012;66:112-5.

2. Alp R, Köktürk A, Gürses I: Hobnail hemanjiyomlu olgu/a case of hobnail hemangioma. Turk J Dermatol 2010;4:78-80.

3. Santa Cruz DJ, Aronberg J: Targetoid hemosiderotic hemangioma. J Am Acad Dermatol 1988;19:550-8.

4. Sahin MT, Demir MA, Gunduz K, Ozturkcan S, Türel-Ermertcan A: Targetoid haemosiderotic haemangioma: dermoscopic monitoring of three cases and review of the literature. Clin Exp Dermatol 2005;30:672-6.

5. Ertam I, Akalin T, Unal I, Ozdemir F: Hobnail haemangioma: dermatoscopic findings facilitating the differential diagnosis. Clin Exp Dermatol 2009;34:e231-3. 